\title{
Processos oxidativos avançados aplicados no tratamento de efluentes da produção de membranas: revisão de literatura
}

\author{
Advanced oxidative processes applied in effluents treatment of membranes production: a review \\ Procesos oxidativos avanzados aplicados en la tratamiento de efluentes de la producción de
} membranas: revisión de literatura

Recebido: 25/03/2021 | Revisado: 30/03/2021 | Aceito: 31/03/2021 | Publicado: 10/04/2021

\author{
Bruna Aline Araújo \\ ORCID: https://orcid.org/0000-0002-9429-6994 \\ Universidade Estadual da Paraíba, Brasil \\ E-mail: brunaaaraujo15@gmail.com \\ José Everton Soares de Souza \\ ORCID: https://orcid.org/0000-0003-0731-534X \\ Universidade Estadual da Paraíba, Brasil \\ E-mail: everton_g3@hotmail.com \\ Kênia Kelly Freitas Sarmento \\ ORCID: https://orcid.org/0000-0001-6815-9577 \\ Universidade Estadual da Paraíba, Brasil \\ E-mail: keniakellys41@gmail.com \\ Larissa Dias Rebouças \\ ORCID: https://orcid.org/0000-0003-3890-6572 \\ Universidade Estadual da Paraíba, Brasil \\ E-mail: larirbcs@gmail.com \\ Keila Machado de Medeiros \\ ORCID: https://orcid.org/0000-0001-9250-1432 \\ Universidade Federal do Recôncavo da Bahia, Brasil \\ E-mail: keilamedeiros@ufrb.edu.br \\ Carlos Antônio Pereira de Lima \\ ORCID: https://orcid.org/0000-0002-1301-6066 \\ Universidade Estadual da Paraíba, Brasil \\ E-mail: caplima@uepb.edu.br
}

\begin{abstract}
Resumo
A aplicação de novas tecnologias e pesquisas em tratamento de águas são os caminhos para minimizar os impactos causados ao meio ambiente e melhoria dos recursos hídricos e, consequentemente, econômico e social de uma região. Dentre as tecnologias, se destacam os processos oxidativos avançados (POA's), os quais são baseados na utilização de espécies altamente oxidantes para promover uma degradação mais eficaz do poluente a ser tratado. Este trabalho tem como objetivo realizar uma revisão dos POA's, sendo eles: a fotocatálise com dióxido de titânio $\left(\mathrm{TiO}_{2}\right)$ /ultravioleta (UV), foto-fenton e o peróxido de hidrogênio $\left(\mathrm{H}_{2} \mathrm{O}_{2}\right) / \mathrm{UV}$, identificando os processos mais adequados de acordo com o poluente a ser tratado. Os POA's se apresentam como uma opção para degradar os poluentes orgânicos que possuem elevada estabilidade química, devido à ineficiência de métodos comuns de tratamento de efluentes de difícil degradação. Além disso, os POA's surgem como uma tecnologia onde apresenta uma maior eficiência no tratamento de efluentes a um baixo custo operacional. Portanto, os POA's possuem um grande potencial para serem aplicados no tratamento de diversos efluentes obtidos a partir dos solventes utilizados na produção de membranas.
\end{abstract}

Palavras-chave: Membranas poliméricas; Inversão de fases; Alternativas sustentáveis; Águas residuárias.

\begin{abstract}
The application of new technologies and research in water treatment are the ways to minimize the impacts caused to the environment and the improvement of water resources and, consequently, the economic and social of a region. Among the technologies, we highlight the Advanced Oxidative Processes (AOP's), which are based on the use of highly oxidizing species to promote a more effective degradation of the pollutant to be treated. This work aims to conduct a review of POA's, which are: Photocatalysis with titanium dioxide $\left(\mathrm{TiO}_{2}\right)$ /ultraviolet (UV), Photo-Fenton and Hydrogen Peroxide $\left(\mathrm{H}_{2} \mathrm{O}_{2}\right) / \mathrm{UV}$, identifying the most suitable processes according to the pollutant to be treated. AOP's are presented as an option to degrade organic pollutants that have high chemical stability, due to the inefficiency of common methods of treating effluents that are difficult to degrade. Furthermore, AOP's appear as a technology where it is more efficient in treating effluents at a low operating cost. Therefore, AOP's have great
\end{abstract}


potential to be applied in the treatment of various effluents obtained from the solvents used in the production of membranes.

Keywords: Polymeric membranes; Phase inversion; Sustainable alternatives; Wastewater.

\begin{abstract}
Resumen
La aplicación de nuevas tecnologías y la investigación en el tratamiento del agua son las formas de minimizar los impactos ocasionados al medio ambiente y la mejora de los recursos hídricos y, en consecuencia, los económicos y sociales de una región. Entre las tecnologías, destacamos los procesos oxidativos avanzados (POA's), que se basan en el uso de especies altamente oxidantes para promover una degradación más efectiva del contaminante a tratar. Este trabajo tiene como objetivo realizar una revisión de los POA, que son: fotocatálisis con dióxido de titanio $\left(\mathrm{TiO}_{2}\right)$ /ultravioleta (UV), foto-fenton y peróxido de hidrógeno $\left(\mathrm{H}_{2} \mathrm{O}_{2}\right) / \mathrm{UV}$, identificando los procesos más adecuados según el contaminante ser tratado. Los POA's son una opción para degradar contaminantes orgánicos que tienen una alta estabilidad química, debido a la ineficacia de los métodos comunes de tratamiento de efluentes que son difíciles de degradar. Además, los POA's emergen como una tecnología donde es más eficiente en el tratamiento de efluentes a un bajo costo operativo. Por tanto, los POA's tienen un gran potencial para ser aplicados en el tratamiento de diversos efluentes obtenidos de los disolventes utilizados en la producción de membranas.
\end{abstract}

Palabras clave: Membranas poliméricas; Inversión de fase; Alternativas sostenibles; Aguas residuales.

\title{
1. Introdução
}

A poluição ambiental passou a ser um assunto de grande interesse, visto que o problema tem se agravado largamente. Os efluentes líquidos, sejam de natureza doméstica ou industrial, são responsáveis por grande parte da carga poluidora do planeta. A implementação de tecnologias mais limpas e pesquisas em tratamento de águas são os caminhos para minimizar os impactos causados ao meio ambiente e melhoria dos recursos hídricos (Pan et al., 2019). O descarte inapropriado desses efluentes tem causado grande preocupação e tem se tornado importante para a comunidade científica que tem como desafio desempenhar processos de reparação para esses danos ambientais (Silva et al., 2014).

As discussões a respeito do meio ambiente estão ficando cada vez mais frequente em todo o mundo juntamente com o tópico das águas naturais, o qual tem se identificado que estas são uma das mais degradadas pela população mundial. Com isso, os órgãos vigentes de controle da qualidade contra os diversos poluentes existentes, estão se tornando cada vez mais rigorosos em diversas localizações do globo terrestre. Tais efluentes quando não tratados de forma correta, além de ser mais uma fonte de poluição, torna possível o aumento considerável dos impactos ambientais e, assim, causar danos praticamente permanentes em toda a biota aquática existente. O impacto que esses efluentes podem causar sobre o meio ambiente é de grande preocupação para as autoridades, pois possuem grande potencial cancerígeno (Rauf et al., 2010).

As principais questões de sustentabilidade ambiental nos setores industriais são a geração de efluentes ou águas residuárias, geralmente com alta demanda biológica de oxigênio (DBO) e demanda química de oxigênio (DQO), e seus processamentos devem levar em consideração as exigências da legislação ambiental inerente ao Conselho Nacional do Meio Ambiente (CONAMA) (Brasil, 2011). Os compostos recalcitrantes ou refratários são substâncias de difícil degradação, ou seja, não são degradados pelos microrganismos comumente existentes em sistemas biológicos de tratamento, sendo então descartados nas vias hídricas receptoras (Dias et al., 2018).

Os processos de tratamentos por membranas são considerados uma tecnologia sustentável, com suas características únicas como um baixo consumo de energia e operação convenientemente compacta. Embora as membranas tenham aumentado a sustentabilidade dos processos químicos, a sua fabricação por si só está longe de ser um processo sustentável. As membranas são definidas como barreiras seletivas que atuam como uma espécie de filtro, separando duas fases, podendo restringir total ou parcialmente o transporte de uma ou várias espécies químicas presentes nas fases. Além disso, são capazes de promover separações onde os filtros comuns não são eficientes (Habert, Borges \& Nóbrega, 2006; Wang et al., 2019).

A fabricação de membranas emprega alguns solventes orgânicos tóxicos, como o ácido fórmico (AF), N-metil-2pirrolidona (NMP) e N,N- dimetilformamida (DMF) pela técnica de inversão de fases que é a mais utilizada para a obtenção de 
membranas poliméricas aplicadas em microfitração (Anadão, 2010). O NMP e o DMF são comumente utilizados para preparar a solução com as matrizes poliméricas polisulfona (PSU) e polietersulfona (PES) e o AF é bastante utilizado para preparar a solução com as poliamidas. Estes solventes misturam-se com a água durante a formação da membrana polimérica e, consequentemente, são geradas quantidades significativas de efluentes contendo tais solventes. Devido à natureza poluidora da fabricação das membranas, tem sido observado que a via de processos a jusante da tecnologia de membranas somente se torna mais sustentável quando a quantidade recuperada de solvente processado for maior que $100 \mathrm{~L} \cdot \mathrm{m}^{-2}$ (Razali et al., 2015).

Para isso, observa-se uma grande necessidade de desenvolver novas maneiras de reduzir os impactos ambientais gerados a partir da obtenção das membranas, com isso foram realizados estudos sobre os Processos Oxidativos Avançados (POA's) que apresentam maior eficiência no tratamento desses efluentes. Os POA's são baseados na utilização de espécies altamente oxidantes para promover uma degradação mais eficaz do poluente a ser tratado, podem ser utilizados em combinação com tratamentos biológicos, com o intuito de aumentar a biodegradabilidade de compostos recalcitrantes diminuindo assim o tempo demandado para o tratamento via processos biológicos tradicionais. Os processos a serem utilizados são a fotocatálise com dióxido de titânio/ultravioleta $\left(\mathrm{TiO}_{2 /} \mathrm{UV}\right)$, peróxido de hidrogênio/UV $\left(\mathrm{H}_{2} \mathrm{O}_{2} / \mathrm{UV}\right)$ e o Foto-Fenton (Fioreze, Dos Santos \& Schmachtenberg, 2014).

Portanto, o efluente gerado a partir da produção de membranas apresenta uma alta carga orgânica, composta por substâncias sintéticas não biodegradáveis, a exemplo do $\mathrm{AF}$, do DMF e do NMP, onde o tratamento por métodos convencionais (coagulação, flotação, sedimentação e adsorção) não é suficiente para tratar as substâncias recalcitrantes presentes neles. A fabricação de membranas produz um volume de água muito grande, pela necessidade da imersão da solução que gera um solvente residual no banho de não solvente, além disso, toda esta água presente no sistema gera uma descarga de efluentes considerável e que precisam passar por tratamentos adequados, eficientes, rápidos e economicamente viáveis.

Diante do exposto, o objetivo deste trabalho é realizar uma revisão bibliográfica sobre os processos oxidativos avançados na degradação dos solventes contidos nos efluentes gerados na produção de membranas, onde são substâncias extremamente agressivas ao meio ambiente.

\section{Metodologia}

Este trabalho constitui de uma revisão bibliográfica de natureza qualitativa realacionada a um estudo sobre os processos oxidativos avançados aplicados no tratamento de efluentes provenientes da produção de membranas existentes na literatura. A pesquisa foi realizada nas principais bases de dados nacionais e internacionais disponíveis na internet (Sciencedirect, Web of Science, Scielo, PubMed e Scopus), contemplando trabalhos acadêmicos e livros-texto especializados e publicados nos últimos anos.

Foram utilizadas as bibliografias onde apresentaram maior interesse para o estudo, sem exclusão de trabalhos por ano de publicação. Este estudo trata de uma revisão temática, centrada na fotocatálise com dióxido de titânio $\left(\mathrm{TiO}_{2}\right) /$ ultravioleta (UV), no processo foto-fenton, no processo que utiliza peróxido de hidrogênio $\left(\mathrm{H}_{2} \mathrm{O}_{2}\right) / \mathrm{UV}$ e na obtenção de membranas poliméricas. Assim, a revisão apresentada é uma síntese dos POA's mais adequados para a degradação dos solventes contidos nos efluentes gerados a partir da produção de membranas pela técnica de inversão de fases.

\section{Resultados e Discussão}

\subsection{Processos Oxidativos Avançados (POA'S)}

Os POA's são processos oxidativos que utilizam diversos radicais livres além do radical hidroxila, como radical sulfato, o íon persulfato, o íon hipoclorito, entre outros, porém o radical hidroxila $(\bullet \mathrm{OH})$ é o mais utilizado. Tais radicais são altamente reativos e não seletivos e são produzidos em quantidades suficientes para oxidar a maioria dos poluentes orgânicos 
presentes nos efluentes. Dessa forma, ao reagir com o oxigênio, dão início a uma série de reações de degradação resultando em espécies inertes, geralmente o $\mathrm{CO}_{2}$ e $\mathrm{H}_{2} \mathrm{O}$ (Arimi et al., 2017).

São métodos utilizados que aceleram o processo de oxidação de substâncias tanto orgânicas quanto inorgânicas resistentes aos meios convencionais de tratamento, tendo a capacidade de removê-las total ou parcialmente, tais processos são caracterizados por ter a capacidade de degradar substâncias recalcitrantes por meio de reações de oxidação que acontecem na geração in situ de radicais livres bastante reativos, principalmente o radical hidroxila $(\cdot \mathrm{OH})$ que são altamente reativas e possuem baixa seletividade de ataque, que é adequado para o uso em tratamento de efluentes recalcitrantes (Bauer et al., 1999; Esplugas et al., 1994).

As vantagens decorrentes do uso dos POA'S são as seguintes (Ameta, 2018):

- Possuem uma alta taxa de reação;

- Têm potencial para reduzir a toxidade e mineralizar totalmente os contaminantes orgânicos;

- Remoção dos compostos refratários;

- Não acumulam resíduos para posterior tratamento como os métodos que utilizam membranas, por exemplo;

- Não criam lodo, como é o caso dos processos físicos, químicos e biológicos;

- Sua baixa seletividade permite o tratamento de diferentes compostos orgânicos por vez;

- Possuem custos relativamente baixos.

Os POA's promissores para degradação e mineralização dos poluentes são: fotocatálise heterogênea $\left(\mathrm{TiO}_{2} / \mathrm{UV}\right)$, peróxido de hidrogênio $\left(\mathrm{H}_{2} \mathrm{O}_{2}\right)$, foto-Fenton $\left(\mathrm{H}_{2} \mathrm{O}_{2} / \mathrm{Fe}^{2+} / \mathrm{UV}\right)$ ozônio $\left(\mathrm{O}_{3}\right)$ e/ou ultravioleta, como também são divididos em sistemas homogêneos e heterogêneos onde são listados no Tabela 1 (Ribeiro et al., 2017).

Tabela 1. Classificação dos POA's.

\begin{tabular}{|c|c|c|}
\hline \multicolumn{3}{|c|}{ Processos Oxidativos Avançados } \\
\hline \multirow{2}{*}{$\begin{array}{l}\text { Sistemas } \\
\text { Homogêneos }\end{array}$} & Com irradiação & $\begin{array}{l}\mathrm{H}_{2} \mathrm{O}_{2} / \mathrm{UV} \\
\text { Foto-Fenton } \\
\mathrm{O}_{3} / \mathrm{UV}\end{array}$ \\
\hline & Sem irradiação & $\begin{array}{l}\mathrm{H}_{2} \mathrm{O}_{2} / \mathrm{Fe}^{2+} \\
\mathrm{O}_{3} / \mathrm{H}_{2} \mathrm{O}_{2} \\
\text { Cavitação }\end{array}$ \\
\hline \multirow{2}{*}{$\begin{array}{l}\text { Sistemas } \\
\text { Heterogêneos }\end{array}$} & Com irradiação & $\begin{array}{l}\mathrm{TiO}_{2} / \mathrm{O}_{3} / \mathrm{UV} \\
\mathrm{TiO}_{2} / \mathrm{H}_{2} \mathrm{O}_{2} / \mathrm{UV} \\
\mathrm{TiO}_{2} / \mathrm{UV}\end{array}$ \\
\hline & Sem irradiação & $\begin{array}{l}\text { Eletro-Fenton } \\
\text { Eletroquímico }\end{array}$ \\
\hline
\end{tabular}

Fonte: Adaptado de Ribeiro et al. (2017).

Os agentes oxidantes mais comumente usados em diferentes POA's e os seus potenciais de oxidação, em volts, estão dispostos na Tabela 2 (AMETA, 2018). Para o tratamento do efluente em laboratório, podemos ilustrar um reator do tipo tanque com capacidade de $1000 \mathrm{~mL}$, com agitação constante em um tempo necessário para que ocorra a degradação, com uma distância do efluente e a fonte de radiação de $0,25 \mathrm{~m}$, localizado sob-radiação UV, consistindo de um sistema em batelada (Figura 1) utilizado para fotocatálise heterogênea com $\mathrm{TiO}_{2} / \mathrm{UV}$ e para fotocatálise homogênea com $\mathrm{H}_{2} \mathrm{O}_{2} / \mathrm{UV}$. 
Tabela 2. Agentes oxidantes comumente utilizados e seus potenciais de oxidação.

\begin{tabular}{lc}
\hline Agente Oxidante & Potencial de Oxidação \\
\hline Flúor & 3,06 \\
Radical Hidroxila & 2,80 \\
Oxigênio Atômico & 2,42 \\
$\mathrm{TiO}_{2}+h v$ & 2,35 \\
Ozônio & 2,08 \\
Persulfato & 2,01 \\
Perbromato & 1,85 \\
Peróxido de Hidrogênio & 1,78 \\
Radical Perhidroxila & 1,70 \\
Hipoclorito & 1,49 \\
Bromato & 1,48 \\
Cloro & 1,36 \\
Dicromato & 1,33 \\
Dióxido de Cloro & 1,27 \\
Permanganato & 1,24 \\
Oxigênio (molecular) & 1,23 \\
Perclorato & 1,20 \\
Bromo & 1,09 \\
Iodo & 0,54 \\
\hline
\end{tabular}

Fonte: Adaptado de Ameta (2018).

Figura 1. Sistema fotocatalítico em batelada.

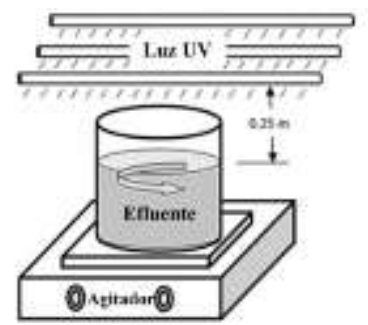

Fonte: Adaptado de Lima et al. (2020).

Para o tratamento do efluente em laboratório por meio da fotocatálise homogênea foto-Fenton, podemos ilustrar, como exemplo, um sistema reacional do tipo tanque que consiste de uma bomba peristáltica e um vaso cilíndrico, fabricado em vidro pyrex, localizado sob as lâmpadas UV, com uma distância do efluente e a fonte de radiação de $0,25 \mathrm{~m}$. No reator fotoquímico, o efluente circula sob agitação magnética em um tempo necessário para que ocorra a sua degradação, conforme apresentado na Figura 2.

Figura 2. Sistema fotocatalítico com recirculação.

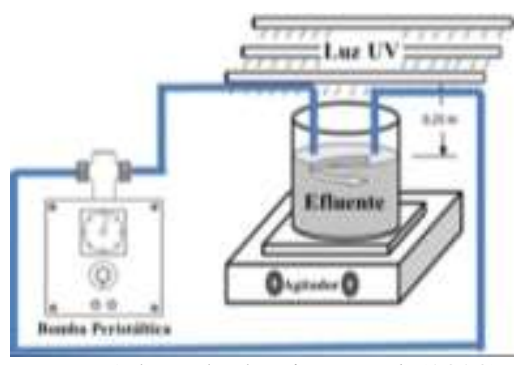

Fonte: Adaptado de Lima et al. (2020). 


\subsection{Fotocatálise Heterogênea $\mathrm{TiO}_{2} / \mathrm{UV}$}

Os sistemas oxidativos heterogêneos se caracterizam pela presença de um catalisador, na maioria das vezes um semicondutor, no qual aumenta a sua velocidade de reação sem alterações (M'bra et al., 2019).

O POA's por fotocatálise com $\mathrm{TiO}_{2} / \mathrm{UV}$ é capaz de oxidar praticamente todos os contaminantes orgânicos por meio de espécies reativas e, ao mesmo tempo, pode não produzir produtos finais perigosos (Athanasekou, Likodimos \& Falaras, 2018).

Esse processo é baseado na absorção de luz pelo semicondutor $\mathrm{TiO}_{2}$ para produzir pares de elétrons, que reagem com a interface e produzem espécies oxidantes como a hidroxila $(\mathrm{OH} \bullet)$ ou radical superóxido, os $\mathrm{OH}$ têm sido considerados como sendo uma espécie de maior atividade durante a reação de oxidação fotocalítica. Entretanto, a utilização de nanopartículas de $\mathrm{TiO}_{2}$ em suspensão é um problema para a recuperação do fotocatalisador após o tratamento. Para resolver tal problema, vários sistemas de fotocatálise que suportam o uso de $\mathrm{TiO}_{2}$ estão em constante desenvolvimento (M'bra et al., 2019).

$\mathrm{O} \mathrm{TiO} 2$ é o semicondutor mais usado na fotocatálise e muitos catalisadores contendo $\mathrm{TiO}_{2}$ foram desenvolvidos para melhorar a produção do $\mathrm{OH} \bullet$, reduzir a energia do gap da banda, retardar a recombinação $\mathrm{e}^{-} / \mathrm{h}^{+}$, aumentar sua área de reação e afinidade por compostos orgânicos e reduzir custos de recuperação do catalisador após o uso (Arcanjo et al., 2018).

As nanopartículas de $\mathrm{TiO}_{2}$ na água são excitadas pela luz UV, gerando $\bullet \mathrm{OH}$ em contato com o oxigênio dissolvido. $\mathrm{O}$ oxigênio é necessário para um processo eficiente de fotocatálise (Afsharnia et al., 2018).

Portanto, o uso de $\mathrm{TiO}_{2}$ oferece uma vantagem sobre os processos de fotólise que utiliza apenas a radiação UV no processo, acelerando a destruição da matéria orgânica indesejável (Mena, Rey \& Beltrán, 2018). A reação de $\mathrm{TiO}_{2}$ na presença de radiação UV é descrita pelas Equações 1, 2 e 3, e pela Figura 3 (Bila, 2008). O processo fotocatalítico tem sido bastante estudado devido sua capacidade de oxidação da matéria orgânica em escala de bancada.

$$
\begin{aligned}
& \mathrm{TiO}_{2}+h v \rightarrow h_{B V}^{+}+e_{B C}^{-} \\
& h_{B V}^{+}+H_{2} \mathrm{O} \rightarrow \mathrm{OH} \bullet+H^{+} \\
& h_{B V}^{+}+\mathrm{OH}^{-} \rightarrow \mathrm{OH} \bullet
\end{aligned}
$$

Figura 3. Esquema da fotocatálise $\mathrm{TiO}_{2}$.

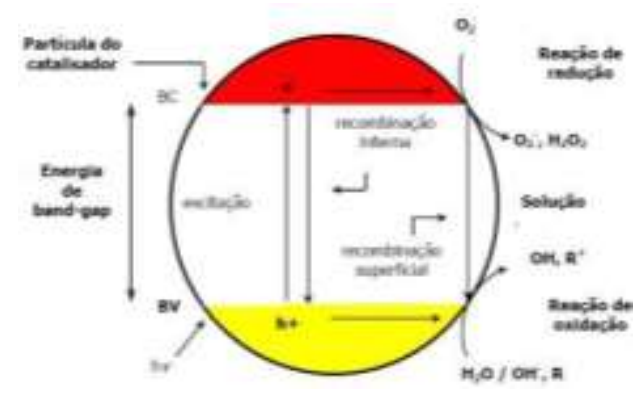

Fonte: Adaptado de Bila (2008).

Lima et al. (2020) avaliaram uma solução de azul de metileno (AM) que foi submetida a um processo fotocatalítico, como base para estudos de compostos mais complexos, como os efluentes de laboratórios de Universidades. AM é um composto padrão para muitos testes fotocatalíticos. $\mathrm{O}$ uso do $\mathrm{TiO}_{2}$ comercial na degradação de compostos tóxicos é muito adequado, pois é barato e eficaz. Portanto, sua caracterização confirmou que suas propriedades físico-químicas atendem a esse propósito. Partículas de $\mathrm{TiO}_{2}$ foram caracterizados por fluorescência de raios-X (FRX), difração de raios-X (DRX), espectroscopia de infravermelho com transformada de Fourier (FTIR), microscopia eletrônica de varredura (MEV) e análise de 
tamanho de partícula. A composição química do dióxido de titânio por FRX indicou uma pureza de 98,6\%. Por meio do DRX, foi possível perceber que o $\mathrm{TiO}_{2}$ apresentou as fases cristalina anatase e rutilo, com predomínio da fase anatase. Por FTIR, duas bandas características de $\mathrm{TiO}_{2}$ foram encontradas em 505 e $612 \mathrm{~cm}^{-1}$. Por MEV, foi visualizado que o $\mathrm{TiO}_{2}$ tinha uma estrutura com partículas esféricas uniformemente distribuídas. A distribuição do tamanho de partícula do $\mathrm{TiO}_{2}$ apresentou diâmetro médio de $2,23 \mu \mathrm{m}$. O processo de degradação do efluente foi avaliado por fotólise e fotocatálise. No processo de degradação do AM por fotólise, foi obtida uma eficiência máxima de 15\% com o uso de três intensidades de irradiação. No processo de fotocatálise, foi observaram que em pH 10,0 e concentração inicial de AM de 2,0 $\mu$ mol. $\mathrm{L}^{-1}$, a fotodegradação foi superior. Isso se deve à superfície das partículas de $\mathrm{TiO}_{2}$ em meio alcalino e à presença de fotocatalisadores promovendo a formação de radicais hidroxila, resultando em eficiência superior a 93,0\%. Portanto, o processo de tratamento ultravioleta (UV) causou uma redução menor na degradação do $\mathrm{AM}$, enquanto a técnica de $\mathrm{UV} / \mathrm{TiO}_{2}$ foi mais eficiente para esta aplicação.

\subsection{Peróxido de Hidrogênio $\left(\mathrm{H}_{2} \mathrm{O}_{2} / \mathrm{UV}\right)$}

Os processos oxidativos combinando $\mathrm{H}_{2} \mathrm{O}_{2} / \mathrm{UV}$, o peróxido de hidrogênio absorve a radiação ultravioleta gerando radicais hidroxilas $(\bullet \mathrm{OH})$ que reagem com os compostos orgânicos presentes no efluente, podendo destruí-los totalmente ou convertê-los em compostos mais simples e inofensivos (Ebrahimi, Gashti \& Sarafpour, 2018).

A eficiência no tratamento de poluentes orgânicos recalcitrantes em efluentes aquosos com utilização de espécies oxidantes precursoras como o peróxido de hidrogênio tem sido investigado sob radiação UV. A aplicação das fontes de radiação UVA e UVB para melhorar o processo de despoluição podem oferecer muitas vantagens. Seguindo essa ideia, complexos de ferro estão sendo usados para iniciar ou melhorar a remoção de poluentes com a utilização de $\mathrm{H}_{2} \mathrm{O}_{2}$ ativado na presença da radiação UV do espectro solar (Huang et al., 2018).

Processos oxidativos avançados com utilização de radiação UV combinam radiação com algum catalisador, a exemplo do peróxido de hidrogênio ou outro promotor de radicais para, simultaneamente, realizar a fotólise e oxidar micropoluentes em águas contaminadas através da produção de radicais hidroxila altamente reativos e não seletivos (Ulliman et al., 2018). A reação do peróxido de hidrogênio na presença de radiação UV está descrito nas Equações 4, 5, 6 e 7:

$$
\begin{aligned}
& \mathrm{HO} \bullet+\mathrm{H}_{2} \mathrm{O}_{2} \rightarrow \mathrm{HO}_{2} \bullet+\mathrm{H}_{2} \mathrm{O} \\
& \mathrm{HO}_{2} \bullet+\mathrm{H}_{2} \mathrm{O}_{2} \rightarrow \mathrm{HO} \bullet+\mathrm{H}_{2} \mathrm{O}+\mathrm{O}_{2} \\
& 2 \mathrm{HO}_{2} \bullet \rightarrow \mathrm{H}_{2} \mathrm{O}_{2}+\mathrm{O}_{2} \\
& \mathrm{HO}_{2} \bullet+\mathrm{HO} \bullet \rightarrow \mathrm{H}_{2} \mathrm{O}+\mathrm{O}_{2}
\end{aligned}
$$

$\mathrm{O}$ excesso de peróxido e com altas concentrações de $\bullet \mathrm{OH}$, ocorrem reações competitivas que produzem um efeito inibitório para a degradação. Os $\bullet \cdot \mathrm{OH}$ podem ser suscetíveis a recombinar-se ou reagem de acordo com as equações citadas. As reações 4 e 7 consomem $\bullet ~ O H$ e diminuem a probabilidade de oxidação. Pode-se determinar uma condição ótima de $\mathrm{H}_{2} \mathrm{O}_{2}$, evitando um excesso que poderia retardar a degradação (Domenech, Jardim \& Litter, 2001).

\subsection{Foto-Fenton}

$\mathrm{O}$ processo foto-Fenton envolve a reação entre os íons de Ferro e peróxido de oxigênio $\left(\mathrm{Fe}^{2+} / \mathrm{Fe}^{3+}+\mathrm{H}_{2} \mathrm{O}_{2}\right)$ para formar espécies reativas capazes de oxidar diferentes componentes orgânicos, assistidos por radiação UV, na presença de luz, uma alta quantidade de $\mathrm{OH} \bullet$ é produzido, elevando o potencial de degradação em comparação com processos não irradiados. Os maiores problemas deste tipo de processo são $\mathrm{pH}$ variando entre 2 e 3 no meio onde a reação ocorre e a presença de carbonatos dentro da água (Guerra et al., 2019; Dias, 2018). 
Para evitar o alto consumo de reagentes envolvidos na operação ao pH 2 ou 3, diferentes complexos de agentes têm sido estudados, os quais permitem o ferro continuar em solução, não permitindo sua precipitação. E a importância de remover os carbonatos da água reside no fato de que eles agem como coletores de radicais $\mathrm{OH}$ (Guerra et al., 2019).

Entretanto, a instabilidade química intrínseca das espécies baseadas no ferro limita as aplicações destes reagentes nas condições severas dos efluentes industriais. Além disso, a alta dosagem de $\mathrm{H}_{2} \mathrm{O}_{2}$ nos reagentes baseados em ferro atuais vem sendo denunciados por meio dos custos e problemas ambientais (Cheng, 2018).

O oxidante primário produzido e responsável pela transformação química na reação Fenton é geralmente considerado o OH• como é possível visualizar na equação 8. Sob condições ácidas (pH menor que 3) na ausência de ligantes orgânicos complexantes, ferro ferroso $\left(\mathrm{Fe}^{2+}\right)$ e férrico $\left(\mathrm{Fe}^{3+}\right)$ solúveis são automaticamente ciclados para produzir $\mathrm{HO}$, conforme visualizado nas equações 9 e 10. Reações de foto-fenton, onde $\mathrm{Fe}^{3+}$ é fotoreduzido a $\mathrm{Fe}^{2+}$ têm se contribuido para aumentar as taxas de remoção de componentes químicos em comparação com a reação fenton sem a presença de luz. Isto ocorre devido a geração de $\mathrm{OH} \bullet$ diretamente pelo fotólise de $\mathrm{H}_{2} \mathrm{O}_{2}$ (Equação 9) e indiretamente pela regeneração de $\mathrm{Fe}^{2+}$ (Equação 10) quando $\mathrm{Fe}^{3+}$ sofre fotorredução para $\mathrm{Fe}^{2+}$ via transferência de carga ligante-metal (Ulliman et al., 2018).

$$
\begin{aligned}
& \mathrm{Fe}^{2+}+\mathrm{H}_{2} \mathrm{O}_{2} \rightarrow \mathrm{Fe}^{3+}+\mathrm{OH}^{-}+\mathrm{OH} \\
& \mathrm{Fe}^{3+}+\mathrm{H}_{2} \mathrm{O}_{2} \rightarrow \mathrm{Fe}^{2+}+\mathrm{HO}_{2}+\mathrm{H}^{+} \\
& \mathrm{Fe}^{3+}(\mathrm{F})_{n}+h v \rightarrow \mathrm{Fe}^{2+}(\mathrm{L})_{n-1}+L^{+}
\end{aligned}
$$

\subsection{Membranas}

As membranas são meios filtrantes que possuem poros de dimensões variadas. Esses poros são responsáveis pelas propriedades que tornam as membranas úteis em suas diversas aplicações, para separar partículas e para fracionar moléculas de diferentes massas molares (Anadão, 2010).

A inversão de fases é a técnica mais utilizada para produção de membranas poliméricas baseando-se na separação de um sistema inicialmente homogêneo em duas fases distintas consistindo de polímero, solvente e eventualmente outros aditivos. A fase sólida ou fase rica em polímero dará origem à matriz da membrana, enquanto que a fase líquida, rica em solvente ou fase pobre em polímero dará origem aos poros (Figoli, Simone \& Drioli, 2015).

No método de imersão-precipitação, a solução é depositada sobre uma placa de vidro e por meio de um bastão de vidro a mesma é espalhada e, posteriormente, a placa é imersa num banho de não solvente, geralmente água (Ferreira et al., 2021). Esse processo ocorre por meio de cinco etapas: preparação de uma solução polimérica, deposição da solução formando um filme fino sobre a placa de vidro, imersão do filme polimérico em um banho de precipitação, remoção do solvente residual presente na matriz polimérica formada e secagem da membrana, conforme ilustrado na Figura 4 (Silva et al., 2021).

Figura 4. Representação das etapas envolvidas na formação de membranas por imersão em banho de não solvente.
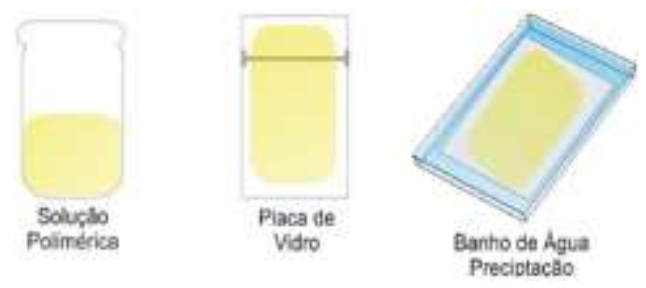

Fonte: Adaptado de Habert, Borges \& Nóbrega (2006). 
A precipitação ocorre porque o solvente é trocado por um não solvente na solução polimérica, este solvente passa para a fase aquosa gerando um grande volume de água contaminada. Portanto, estas águas apresentam-se quimicamente inadequadas para serem lançadas em qualquer corpo hídrico sendo, do ponto de vista de preservação ambiental e surgindo a necessidade de estudos de tratamento destes, tanto para o descarte, como a possibilidade de reuso da água tratada no próprio processo (Gohil \& Choudhury, 2019).

Os solventes orgânicos mais usados no processo de obtenção de membranas são o DMF, o NMP e o AF, onde eles podem causar sérios problemas de saúde em quem entra em contato com tais substâncias, entre os perigos associados são que seus líquidos e vapores são inflamáveis, são prejudiciais se em contato com a pele, olhos e sistema respiratório, causando sérias irritações, podendo afetar até o desenvolvimento de fetos, a exemplo de má formação (Figoli et al., 2014).

Estima-se que cerca de 50 bilhões de litros de efluentes contaminados com solventes são gerados decorrentes da produção de membranas, fazendo com que seu sistema de produção não seja considerado uma tecnologia limpa. Por isso, a toxidade, os fatores de produção, a exemplo dos fatores técnicos, econômicos e ambientais, devem ser levados em consideração na escolha do melhor solvente a ser utilizado (Wang et al., 2019).

Apesar do grande interesse da comunidade acadêmica e empresarial na produção de membranas poliméricas, onde inúmeros trabalhos estão sendo desenvolvidos e publicados, observa-se que quase nenhum aborda o problema dos efluentes gerados nos processos de obtenção deste produto. O processo de obtenção destas membranas pela técnica de inversão de fases a partir do método de imersão-precipitação produz um volume considerável de efluentes inadequados para serem descartados diretamente nos corpos receptores de água, então surge à necessidade de estudos de tratamento destes, tanto para o descarte, como para possibilidade de reuso do efluente tratado no próprio processo.

$\mathrm{O}$ tratamento de efluentes gerados na produção de membranas é necessário, pois o mesmo é altamente prejudicial ao meio ambiente devido entre outros fatores à elevada DQO, e presença de vários compostos químicos como ácidos orgânicos (Razali et al., 2015). Entre os métodos que estão sendo desenvolvidos para descontaminação de efluentes de difícil degradação, temos os POA'S, que tem merecido especial atenção, e que se baseia principalmente na formação de radicais hidroxilas $(\mathrm{OH} \bullet)$, que podem oxidar e mineralizar compostos orgânicos e reduzir metais, a partir da combinação de diferentes oxidantes químicos com uma fonte de irradiação, para a geração dos referidos radicais.

\subsection{POA's Utilizados no Tratamento de Efluentes Gerados na Produção de Membranas}

A partir do estudo na literatura, foi possível identificar vários tipos de tratamentos através dos POA's, com o intuito de degradar a matéria orgânica presente nos efluentes que contêm solventes utilizados na produção de membranas.

Wang, Shiraishi e Nakano (2002) avaliaram o efeito sinérgico da fotocatálise e da ozonização na decomposição do AF dissolvido em uma solução aquosa, conforme ilustrado na Figura 5. O processo fotocatalítico, as taxas de decomposição inicial seguiram o tipo Langmuir-Hinshelwood e o peróxido de hidrogênio gerado durante a reação fotocatalítica desempenhou um papel importante na decomposição do ácido fórmico. Já para a ozonização, a taxa de decomposição do ácido fórmico foi maior para uma menor temperatura do líquido e um maior valor de $\mathrm{pH}$. Os valores experimentais obtidos na ozonização sozinha e na combinação de fotocatálise e ozonização foram comparados utilizando-se também o tipo Langmuir-Hinshelwood. Os resultados obtidos pelos autores indicaram que a taxa de decomposição do ácido fórmico pela combinação de fotocatálise e ozonização foi de $31 \%$ maior do que a soma das taxas de decomposição quando o ácido fórmico foi decomposto individualmente pelos dois métodos, indicando a presença de um efeito sinérgico da fotocatálise e da ozonização. Assim, esse efeito pôde ser explicado pela produção de radicais hidroxilas pelo ozônio sobre o óxido de titânio. 
Figura 5. Sistema de um reator para fotocatálise combinada e ozonização em decomposição de ácido fórmico.

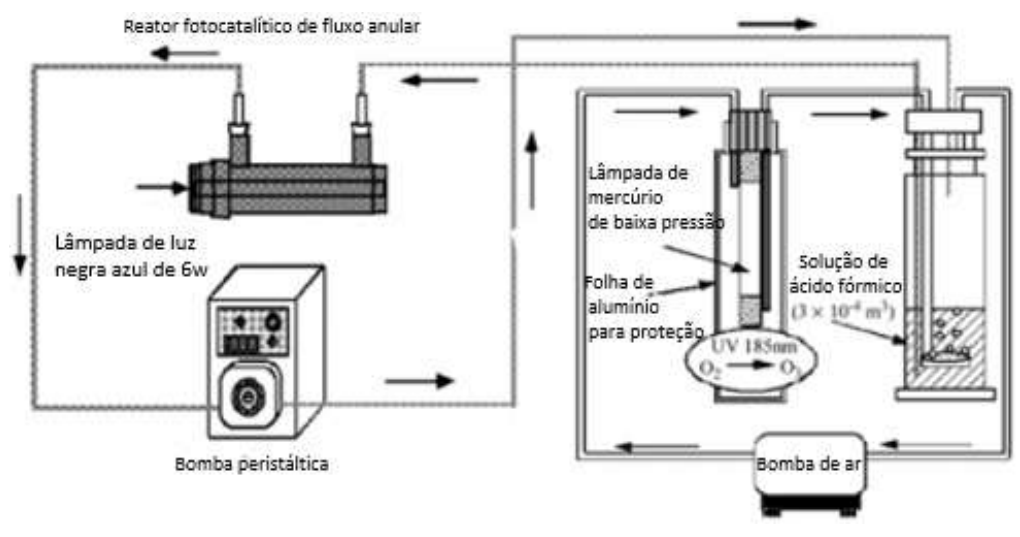

Fonte: Wang et al. (2002).

Chang et al. (2005) estudaram a oxidação fotocatalítica do DMF utilizando um fotorreator anular de fluxo de tampão revestido com dióxido de titânio como mostra a Figura 6, o solvente foi utilizado na fabricação de couro e têxtil sintético. Para descrever o decaimento da atividade do catalisador foi utilizado o modelo cinético de desativação de Levenspiel, caracterizaram a superfície e o mecanismo de desativação do fotocatalisador pela espectroscopia de infravermelho por transformada de Fourier (FTIR). Seus resultados revelaram que os ácidos carbonílicos, aldeídos, aminas, carbonatos e nitratos foram adsorvidos na superfície do $\mathrm{TiO}_{2}$ durante a reação fotocatalítica. Os íons $\mathrm{NH}_{4}^{+} \mathrm{e} \mathrm{NO}_{3}^{-}$, que causaram a desativação de catalisadores, foram detectados na superfície do $\mathrm{TiO}_{2}$. Diversos processos de tratamento foram aplicados para encontrar um procedimento adequado para a regeneração da atividade catalítica e o mais adequado foi o processo utilizando o $\mathrm{H}_{2} \mathrm{O}_{2} / \mathrm{UV}$.

Figura 6. Montagem do aparelho experimental: (1) cilindro de gás $\left(\mathrm{N}_{2}\right.$ e $\left.\mathrm{O}_{2}\right)$; (2) controlador de fluxo de massa; (3) bomba de seringa; (4) aquecedor; (5) misturador; (6) reator fotocatalítico; (7) sensor de ponto de orvalho; (8) GC/FID; (9) computador; (10) válvula de amostragem.

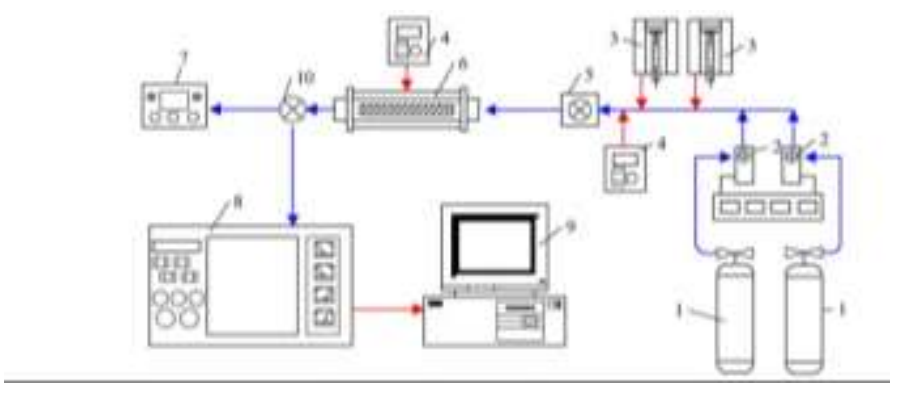

Fonte: Chang et al. (2005).

Mrowetz e Selli (2006) avaliaram a degradação fotocatalítica do ácido fórmico (AF) e do ácido benzóico (AB), escolhidos como modelo de moléculas orgânicas com propriedades ácidas, e que foram investigados em suspensões aquosas de $\mathrm{TiO}_{2}$ e óxido de zinco $(\mathrm{ZnO})$ em diferentes condições experimentais. A evolução do peróxido de hidrogênio, formado por meio de um redutor via iniciada por elétrons da banda de condução, também foi monitorada simultaneamente durante as execuções de degradação. O efeito de diferentes valores iniciais de substratos e a dependência da taxa de reação no pH inicial das suspensões de $\mathrm{TiO}_{2}$ foi interpretada sob a luz de um pseudo-estável estado Langmuir-Hinshelwood, taxa de forma e das interações eletrostáticas que ocorrem na interface água-semicondutor. $\mathrm{O} \mathrm{ZnO}$ pareceu o fotocatalisador mais eficaz do que $\mathrm{TiO}_{2}$ para $\mathrm{AB}$, mas não para degradação de $\mathrm{AF}$. Uma quantidade muito maior de peróxido de hidrogênio foi detectada em $\mathrm{ZnO}$ 
irradiado em suspensões, tanto na presença quanto na ausência dos substratos, principalmente por causa de sua menor taxa de decomposição fotocatalítica nesse óxido. A taxa de evolução do peróxido de hidrogênio durante a oxidação fotocatalítica do $\mathrm{AB}$ em $\mathrm{TiO}_{2}$ pode estar relacionada à taxa do processo de oxidação, enquanto o $\mathrm{H}_{2} \mathrm{O}_{2}$ não pôde ser detectado durante a degradação fotocatalítica do AF neste óxido, principalmente por causa da capacidade de blindagem reduzida deste substrato.

Miller et al. (2010) analisaram o efeito da água na adsorção e decomposição fotocatalítica (DF) do ácido fórmico no $\mathrm{TiO}_{2}$ e platina $(\mathrm{Pt}) / \mathrm{TiO}_{2}$ foi investigado usando estudos de reação transitória, dessorção programada por temperatura (DPT), e espectroscopia de infravermelho com transformada de Fourier (FTIR). Estudos de reação indicaram que a água fisissorvida aumentou a taxa de $\mathrm{DF}$ do ácido fórmico em uma pequena extensão no $\mathrm{TiO}_{2}$ e em grande parte na $\mathrm{Pt} / \mathrm{TiO}_{2}$, mas esse efeito não ocorreu apenas na presença de água quimicamente adsorvida. A espectroscopia de FTIR e estudos de DPT indicaram que o principal efeito da adição de água ao $\mathrm{TiO}_{2}$ que continha ácido fórmico adsorvido foi o deslocamento do ácido fórmico. No entanto, a espectroscopia de FTIR indicou que a adição de água causou uma mudança no adsorvido e na estrutura de formato que pode estar associada à maior reatividade. Essas transformações podem ter uma influência importante nas etapas elementares da decomposição fotocatalítica do ácido fórmico no $\mathrm{TiO}_{2}$ e $\mathrm{Pt} / \mathrm{TiO}_{2}$.

Zolfaghari, Mortaheb e Meshkini (2011) realizaram a degradação do solvente NMP por meio do processo fotocatalítico $\mathrm{TiO}_{2} / \mathrm{UV}$ através do diagrama apresentado na Figura 7. Alguns parâmetros foram analisados como: os efeitos da carga do fotocatalisador de $\mathrm{TiO}_{2}$, temperatura, $\mathrm{pH}$, concentração inicial e o tipo de fase gasosa na taxa de reação, e foram definidas as condições ideais para a taxa máxima de degradação. Observou-se que os resultados desses parâmetros influenciam diretamente na degradação do NMP. A carga ideal do $\mathrm{TiO}_{2}$ foi de $0,1 \%$ em peso, onde verificou-se que forneceu uma área de superfície suficiente para a reação em perda de irradiação devido a dispersão da luz UV. A taxa de reação de fotodegradação mais alta foi obtida em condição neutra ou levemente ácida, em vez da faixa ácida ou alcalina extrema. A expressão da taxa de reação de pseudo-primeira ordem do modelo de Langmuir-Hinshelwood simulou o processo de degradação fotocatalítica.

Figura 7. Diagrama esquemático do fotorreator em lote.

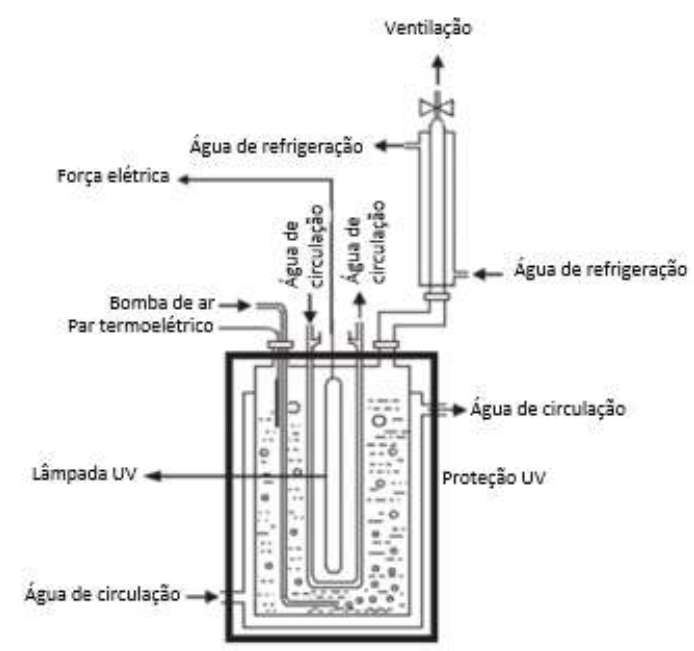

Fonte: Zolfaghari, Mortaheb e Meshkini (2011).

Mariani et al. (2013) desenvolveram um modelo cinético para a degradação simultânea de ácido dicloroacético (ADCA) e ácido fórmico (AF), como mostra a Figura 8. A oxidação foi produzida pela combinação de peróxido de hidrogênio (PH) e ultravioleta com radiação $(253,7 \mathrm{~nm})$. Um conjunto de quatro equações, três diferenciais e uma algébrica, representou o tempo de evolução da concentração de $\mathrm{ADCA}, \mathrm{AF}, \mathrm{PH}$ e do ácido clorídrico $(\mathrm{HCl})$. O modelo foi baseado em um mecanismo de reação completo, que compreende a fotólise do peróxido de hidrogênio e a decomposição dos ácidos dicloroacético e 
fórmico. Foi levado em consideração o efeito da distribuição não uniforme da taxa local de fótons absorvidos. $\mathrm{O}$ modelo matemático simulou os dados experimentais. Também foi mostrado que o AF decaiu muito mais rápido do que o ADCA.

Figura 8. Diagrama experimental.

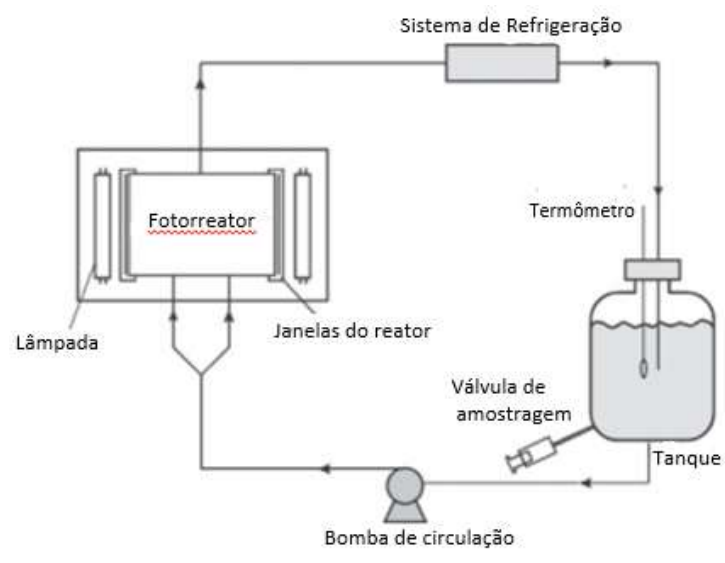

Fonte: Mariani et al. (2013).

Wan et al. (2013) estudaram a degradação do Bisfenol A (BPA) que possui compostos intermediários aromáticos e alguns ácidos alifáticos de cadeia curta resultantes da clivagem aromática incluindo o ácido fórmico. No estudo da fotodegradação de BPA utilizando eletrodos de $\mathrm{TiO}_{2}$ e óxido de tungstênio $\left(\mathrm{WO}_{3}\right)$ na presença de $\mathrm{Fe}^{3+} \mathrm{e} \mathrm{Cu}^{2+}$, verificou-se que o comportamento dos íons são muito dependentes da atividade fotocatalítica do óxido do metal utilizado. $\mathrm{Com}_{\mathrm{TiO}_{2}}$ (anatase e rutilo), todos os perfis de tempo de degradação de fenol na água sob irradiação ultravioleta seguiram uma equação de velocidade de primeira ordem. $\mathrm{Na}$ adição de $\mathrm{Cu}^{2+}$, a degradação de fenol em $\mathrm{TiO}_{2}$ e $\mathrm{WO}_{3}$ também seguiu a cinética de primeira ordem. $\mathrm{Na}$ adição de $\mathrm{Fe}^{3+}$, a velocidade inicial de degradação do fenol foi aumentada, mas apenas as reações no $\mathrm{TiO}_{2}$ seguiram uma cinética de primeira ordem após meia hora. As constantes de velocidade para a degradação de fenol na presença de $\mathrm{Fe}^{3+}$ ou $\mathrm{Cu}^{2+}$ foram maiores do que na ausência dos íons metálicos. A adição dos íons quando se utilizou o $\mathrm{WO}_{3}$ também aumentou a degradação do BPA e, consequentemente, do ácido fórmico.

Turki et al. (2014) avaliaram nanomateriais $1 \mathrm{D}-\mathrm{TiO}_{2}$ (nanotubos, nanobastões, nanoplacas, nanoesferas e nanopartículas) com propriedades estruturais e texturais ajustadas para degradação fotocatalítica de ácido fórmico (AF) em condições de UV. As isotermas de adsorção do AF seguem o modelo de Langmuir e a cinética de fotodegradação do AF mostra o modelo de Langmuir-Hinshelwood independentemente das morfologias do $\mathrm{TiO}_{2}$. Nanotubos de $\mathrm{TiO}_{2}(\mathrm{HTNT}-400)$, nanoplacas (HTNW-700) e nanopartículas (HTNT-500 e HTNT-600) mostraram atividades fotocatalíticas interessantes em comparação com nanoesferas de $\mathrm{TiO}_{2}$ (P25) e nanobastões (TNR). O TiO 2 nanotubular (HTNT-400) possuiu uma atividade fotocatalítica 4 vezes maior que o $\mathrm{TiO}_{2} \mathrm{P} 25$. A atividade intensificada foi atribuída ao menor tamanho de cristalito da anatase e área de superfície ajustada do fotocatalisador. $\mathrm{O}$ estudo de $\mathrm{pH}$ mostrou que a coexistência de espécies de $\mathrm{HCOO}^{-}$e do $\mathrm{HCOOH}$ em pH natural $(3,5)$ foi favorável para melhorar a adsorção em sítios ativos do óxido de titânio e sua atividade fotocatalítica.

Parrino et al. (2014) aplicaram a fotocatálise heterogênea e a ozonização individualmente e em combinação, através de um processo integrado para degradar os compostos orgânicos com ácido fórmico em água contendo também ânions de brometo conforme ilustrado na Figura 9. Os resultados mostraram que a fotocatálise única não produz íons bromato e, na sua presença, é capaz de reduzir o bromato a íons de brometo inócuos. Assim, com a integração da fotocatálise e ozonização aumentou sinergicamente as capacidades de oxidação. E também, no processo integrado os íons bromato não são produzidos enquanto alguns orgânicos oxidáveis estiverem presentes. 
Figura 9. Esquema do sistema reagente.

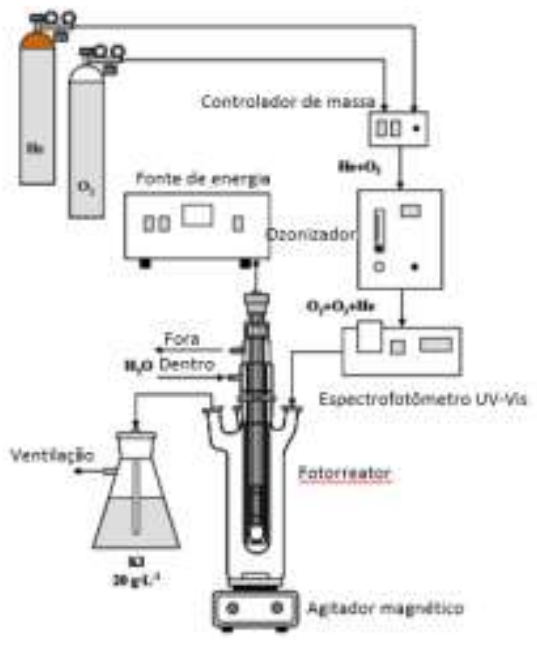

Fonte: Parrino et al. (2014).

Ma et al. (2015) investigaram a cinética e o mecanismo de degradação do ácido fórmico ( $\left.\mathrm{HCOO}^{-}\right)$com partículas semicondutoras de cloreto de prata $(\mathrm{AgCl})$ mediante a presença de luz. Os resultados experimentais mostraram que irradiação de luz de $\mathrm{AgCl}_{(\mathrm{s})}$ resultou na geração de buracos e elétrons com o orifícios e seu radical carbonato de produto de oxidação inicial, oxidando $\mathrm{HCOO}^{-}$para formar $\mathrm{CO}_{2}$. A taxa de degradação do $\mathrm{HCOO}^{-}$aumentou a concentração de prata devido ao aumento na taxa de foto-geração de buracos, enquanto o aumento na concentração de cloreto diminuiu com a taxa de degradação de $\mathrm{HCOO}^{-}$como resultado da eliminação de buracos pelo $\mathrm{Cl}^{-}$, resultando assim, na diminuição dos buracos e na concentração de radical carbonato, ilustrado na Figura 10. Os resultados obtidos indicaram que uma variedade de outras condições de solução, incluindo a concentração de oxigênio, concentração de bicarbonato e pH influenciam a disponibilidade de orifícios e, portanto, a taxa de degradação $\mathrm{HCOO}^{-}$. Com base nos resultados experimentais, foi desenvolvido um modelo cinético capaz de prever a fotodegradação do $\mathrm{HCOO}^{-}$mediada por $\mathrm{AgCl}_{(\mathrm{s})}$ em uma ampla gama de condições.

Figura 10. Esquema do mecanismo de reação para a degradação de $\mathrm{HCOO}$ na irradiação de $\mathrm{AgCl}$ (s).

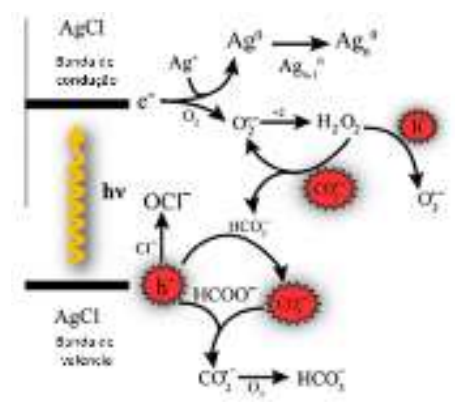

Fonte: Ma et al. (2015).

El-Alami et al. (2017) estudaram o efeito da fluoração de dois catalisadores de $\mathrm{TiO}_{2}$, ambos com a mesma área superficial, mas um composto apenas de fase anatase pura (SA) e o outro de fases anatase e rutilo mistas (P25), na degradação do fenol, ácido fórmico e anilina. Os autores caracterizaram os catalisadores por FTIR, área superficial específica (BET), análise de energia dispersiva de raios-X (EDAX), microscopia eletrônica de varredura (MEV), difração de raios-X (DRX) e espectroscopia de refletância difusa de ultravioleta visível (DRS-UV-vis). O método utilizado pelos autores para a síntese do F-P25 e F-SA resultou em catalisadores fluorados com propriedades diferentes de outros catalisadores fluorados relatados na 
literatura. Os resultados obtidos mostram que, ao contrário de outros estudos em que a formação de radicais hidroxilas livre $(\bullet \mathrm{OH}$ livre) foi potencializada com os catalisadores fluorados. Nos catalisadores F-P25 e F-SA ocorreram à formação de radicais hidroxilas de superfície $\left(\cdot \mathrm{OH}_{\text {superfíieie }}\right)$ que foi significativamente melhorado. Desta forma, os catalisadores F-P25 e FSA deram as maiores constantes de taxa de degradação de fenol, anilina e ácido fórmico do que os catalisadores P25 e SA.

Hamandi, Berhault e Kochkar (2017) prepararam os fotocatalisadores de óxido de grafeno (OG)/ $/ \mathrm{TiO}_{2}$ usando amostras de dióxido de titânio $\left(\mathrm{TiO}_{2}\right)$ obtidas pela mistura física de diferentes quantidades de anatase e rutilo. As misturas de anatase/rutilo foram então suportadas por $\mathrm{OG}$ ou óxido de grafeno reduzido (OGr). A atividade fotocatalítica desses materiais foi investigada na fotodegradação do ácido fórmico como modelo de reação sob irradiação de luz UVA. As amostras de $\mathrm{GOr} / \mathrm{TiO}_{2}$ contendo as fases anatase e rutilo mostraram atividades mais elevadas do que a anatase pura, apresentado na Figura 11, o máximo sendo alcançado com $88 \%$ de anatase e $12 \%$ de rutilo. Esse sinergismo entre a fase anatase e rutilo é foi amplificado com a adição do óxido de grafeno em sua forma reduzida. Este efeito do aumento foi explicado principalmente em termos de transferência de elétrons de anatase para rutilo e, em seguida, óxido de grafeno ou óxido de grafeno reduzido. A este respeito, a redução parcial do óxido de grafeno parece uma maneira notável de evitar a recombinação de pares elétron-buraco fotogerados. No entanto, a transferência de carga foi eficiente apenas se o rutilo estivesse presente nas amostras de $\mathrm{TiO}_{2}$.

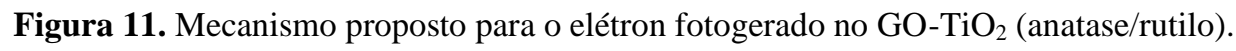

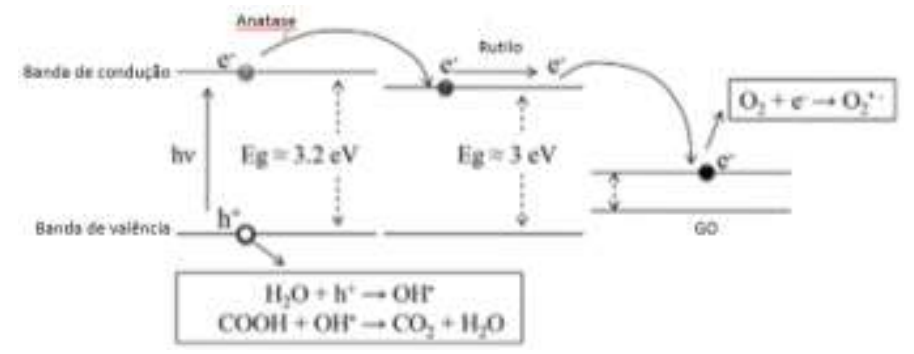

Fonte: Hamandi, Berhault e Kochkar (2017).

Hérissan et al. (2017) realizaram a análise da redução fotocatalítica heterogênea de nitrato $\left(\mathrm{NO}^{3-}\right)$ na presença de $\mathrm{AF}$ usando amostras de $\mathrm{TiO}_{2}$ puras e modificadas sob irradiação UV-vis em pH 3, como também a evolução dos produtos intermediários. Os autores relataram a formação de nitrito em todos os casos, mas em pequenas quantidades, e sua concentração desprezível $\leq 1 \mu \mathrm{M}$ ) após a redução completa de $\mathrm{NO}^{3-}$. Ainda, o amônio foi encontrado como produto final e em quantidades consideráveis ao final da irradiação. Como também, o balanço de nitrogênio foi responsável por uma grande quantidade de produtos de nitrogênio não identificados formados durante a reação fotocatalítica, provavelmente $\mathrm{N}_{2}$ ou NO; esta quantidade foi maior para as amostras puras P25 e PC500. Portanto, foi constatado que a eficiência do uso de AF como doador foi avaliada e o PC500 mostrou-se mais eficiente neste sentido.

Riboni et al. (2017) estudaram fotocatalisadores de óxido misto $\mathrm{TiO}_{2}$ e Ti-W, com razões molares W/Ti na faixa de 0 a $5 \%$, foram preparados por meio de um método sol-gel simples, seguido de recozimento a 500 ou $700{ }^{\circ} \mathrm{C}$, e sua fotoatividade foi testada na foto-oxidação do ácido fórmico na fase aquosa sob condições aeróbicas ambientais. A análise de difração de raios- $\mathrm{X}$ em pó evidenciou que na presença de tungstênio a fase anatase era estável mesmo após calcinação a $700{ }^{\circ} \mathrm{C}$, com uma área de superfície progressivamente maior e menores dimensões de partícula com teor crescente de tungstênio. O tungstênio pode entrar na rede de titânia, conforme demonstrado pela análise microscopia eletrônica de transmissão e de varredura de imagem anular de campo escuro de alto ângulo, e também segregar como $\mathrm{WO}_{3}$ amorfo na superfície dos fotocatalisadores, conforme sugerido pela análise da espectroscopia de fotoelétrons excitados por raios-X. O fotocatalisador de óxido de Ti/W de melhor desempenho é aquele contendo 1,0\% de mol W/Ti, principalmente devido ao efeito de estabilização induzido pelo 
tungstênio da fase anatase, enquanto a transferência de elétrons de $\mathrm{TiO}_{2}$ para o tungstênio $\left(\mathrm{WO}_{3}\right)$, embora compatível com as medições de ressonância paramagnética eletrônica aqui realizadas, pareceu não ter efeito benéfico na reação investigada, provavelmente devido ao baixo nível de energia da banda de condução de $\mathrm{WO}_{3}$, da qual os elétrons não podem ser transferidos de forma eficiente para o oxigênio adsorvido.

Chen et al. (2018) avaliaram os efeitos da taxa de carga orgânica (OLR) para remoção de DMF, m-Cresol (MC) e álcool isopropílico (IPA) por um biorreator de membrana anaeróbia em escala piloto (AnMBR) para tratar águas residuais de solventes de base química sintética de antibióticos em um período de melhora da concentração da Demanda Química de Oxigênio (DQO) com diminuição do Tempo de Retenção Hidráulica (TRH). Ao longo dos 249 dias de tempo de operação, a eficiência média de remoção de DMF, MC e IPA foi de 96,9\%, 98,2\% e 96,4\%, respectivamente. A camada acumulada na superfície da membrana atuou como um biofilme secundário dinâmico que levou ao aumento da taxa de remoção física. Além disso, modelos estatísticos matemáticos foram construídos sobre técnicas de regressão linear para explorar a relação interna entre EPS e o desempenho do AnMBR.

No processo de fabricação das membranas poliméricas, o solvente N-metil-2-pirrolidona (NMP) é bastante utilizado, com uma concentração alta sendo maior que $1000 \mathrm{mg} \cdot \mathrm{L}^{-1}$. O seu descarte nas águas residuais é bastante preocupante, logo se faz necessário um tratamento devido a possíveis impactos ambientais negativos. Loh et al., 2018, estudaram uma maneira para tratar as águas residuais do processo de fabricação das membranas contendo uma maior concentração de NMP por um reator de batelada sequencial (SBR) como também por um biorreator de membrana (MBR). Os autores concluíram que o tratamento através do SBR foi capaz de remover mais de 90\% de carbono orgânico dissolvido e aproximadamente 98\% do NMP em 2 horas de experimento. Porém, o experimento MBR mostrou uma diminuição da eficiência de $100 \%$ para 40\% no período de 15 dias de operação.

Negishi et al. (2019) avaliaram os efeitos do silicato de sódio $\left(\mathrm{SiO}_{3}\right)$ em água em um fotocatalisador de cerâmica com $\mathrm{TiO}_{2}$, foi determinado os efeitos do $\mathrm{SiO}_{3}$ na taxa de degradação fotocatalítica do ácido fórmico (como um contaminante modelo) e na taxa de inativação fotocatalítica de Escherichia coli em solução aquosa. Tanto a taxa de degradação do ácido fórmico quanto a taxa de esterilização diminuiu com o aumento da concentração de $\mathrm{SiO}_{3}$. Por outro lado, em uma dada concentração do $\mathrm{SiO}_{3}$, a atividade do fotocatalisador não diminuiu ao longo de $120 \mathrm{~h}$, e a estrutura da superfície do fotocatalisador não mudou (ou seja, nenhum precipitado foi formado na superfície). As diminuições na atividade fotocatalítica devido à presença de $\mathrm{SiO}_{3}$ poderia ser recuperado por lavagem do aparato experimental com água destilada. Esses resultados mostraram que a razão para a menor atividade fotocatalítica na presença de $\mathrm{SiO}_{3}$ do que em sua ausência foi devido à adsorção de $\mathrm{SiO}_{3}$ na superfície do fotocatalisador de $\mathrm{TiO}_{2}$ e que a adsorção do $\mathrm{SiO}_{3}$ foi o resultado do processo de equilíbrio na água.

Dou et al. (2019) analisaram um novo processo para remoção do DMF em efluentes industriais, sua baixa degradabilidade demanda um tratamento eficaz. Utilizaram um processo que combine com extração, destilação e osmose inversa. Para a extração do DMF usou o clorofórmio, após a extração do DMF foi utilizado a querosene para remoção do clorofórmio dissolvido nos efluentes industriais. No processo da destilação foram projetados extratores para a separação e recuperação do DMF, as simulações mostraram que mais de $99 \%$ do DMF poderia ser recuperada com sua pureza de $99 \%$. A salinidade das águas residuais teve uma redução para um nível muito mais baixo através do processo de RO, e a qualidade dos efluentes melhorou bastante. Portanto, a análise econômica mostrou que uma redução significativa de $72,74 \%$ no custo anual total (TAC) pode ser obtida usando o processo proposto.

Sang et al. (2019) analisaram a degradação do DMF utilizando um plasma de descarga de barreira dielétrica (DBD). Através do plasma DBD $1000 \mathrm{mg} \mathrm{L}^{-1}$ de DMF podem ser degradados sob diferentes potências de entrada, tempo de tratamento e valores iniciais de $\mathrm{pH}$ da solução aquosa, depois de 40 minutos com uma descarga plasmática de DBD foram alcançada uma eficiência de degradação de 52,2\% na concentração de DMF de $1000 \mathrm{mg} \mathrm{L}^{-1}$ com uma potência de entrada de $16,19 \mathrm{~W}$ sob pH 
inicial de 11,14 em solução aquosa, e a eficiência energética do sistema foi de $13,2 \mathrm{mg} \mathrm{kJ}^{-1}$, já a eficiência da remoção diminuiu com a presença de radicais, manifestando que o $\mathrm{OH}$ desempenha um papel crítico no processo de degradação.

Kwon, Lin e Iglesia (2020) analisaram os detalhes do mecanismo das rotas de decomposição do HCOOH. Essas rotas também foram amplamente utilizadas como uma sonda das propriedades ácido-base da superfície dos óxidos. Além disso, foi estudado a identidade por espectros de infravermelho das amostras de $\mathrm{TiO}_{2}$ contendo $\mathrm{HCOOH}$ e a relevância cinética dos intermediários ligados. Essas rotas de desidratação foram consistentes com a superfície química esperada para pares ácido-base de Lewis na superfície do $\mathrm{TiO}_{2}$ sem a necessidade da presença ou envolvimento de centros reduzidos ou titanóis no ciclo catalítico. As rotas de reação mostraram espécies fortemente ligadas e evidentes na presença e na natureza não reativa do espectro de infravermelho in-situ, fornecendo um modelo orgânico permanente para reações de espécies fracamente ligadas que são frequentemente invisíveis em espectroscopia. Portanto, foi constatado que ocorreu a decomposição do $\mathrm{HCOOH}$ na superfície do $\mathrm{TiO}_{2}$, fornecendo informações valiosas sobre as reações que envolveram os intermediários, para formar produtos de $\mathrm{CO}$ e $\mathrm{H}_{2} \mathrm{O}$ sem a formação detectável de produtos de desidrogenação.

Pascoal et al. (2020) observaram que as membranas de poliamida desempenham um papel importante nos processos de separação. Entretanto, a produção dessas membranas gera efluentes contaminados com alta concentração de ácido fórmico (AF), que é facilmente oxidado e altamente tóxico ao meio ambiente. O dióxido de titânio $\left(\mathrm{TiO}_{2}\right)$ utilizando radiação ultravioleta (UV) é uma alternativa promissora para o tratamento de efluentes contaminados por compostos orgânicos. O objetivo deste artigo é tratar um efluente gerado a partir da produção de membranas poliméricas, pelo processo fotocatalítico. Através das análises físico-químicas 1.993,13 mg O $\mathrm{L}^{-1}$ foram obtidos para DQO e 106,45 $\mathrm{mmol} \mathrm{L}^{-1}$ de teor de AF para o efluente bruto. $\mathrm{O}$ tratamento por radiação UV apresentou baixa degradação do $\mathrm{AF}$, enquanto a técnica com $\mathrm{TiO}_{2} / \mathrm{UV}$ foi mais eficiente, atingindo $89,5 \%$ de degradação do AF e 79,44\% da DQO, apresentando-se como um processo bastante promissor para a degradação desse efluente.

Sadi et al. (2020) estudaram as atividades fotocatalíticas de materiais de dióxido de titânio na degradação do ácido fórmico (AF) como molécula modelo sob UV. Os raios-X e Raman mostraram o sucesso da formação da fase anatase em baixa temperatura sem qualquer pós-calcinação. A análise de infravermelho com refletância atenuada total confirmou o enxerto do ácido cianúrico $(\mathrm{AC})$ em $\mathrm{TiO}_{2}$ identificado pela formação da banda de vibração entre Ti e triazina. $\mathrm{O}$ mapeamento por microscopia eletrônica de varredura mostrou que $\mathrm{C}, \mathrm{O}$, Ti e $\mathrm{N}$ estão homogeneamente distribuídos no nanomaterial. A fotoluminescência e a espectroscopia de UV-visível mostraram (i) a captura de elétrons pela vacância de oxigênio identificada por espectroscopia de Raman e (ii) o buraco foi confinado pelo nitrogênio. Portanto, o elétron excitado pode mover-se do $\mathrm{TiO}_{2}$ para os novos subníveis iniciados pela introdução de nitrogênio que resultou na extinção da intensidade da fotoluminescência. As atividades fotocatalíticas dos vários nanomateriais aumentaram em relação ao carregamento de AC, e consequentemente, aumentando a degradação fotocatalítica AF.

\section{Considerações Finais}

Os processos de separação por membranas são bastante utilizados no tratamento de efluentes, porém a preparação das membranas pela técnica de inversão de fases resulta na produção de efluentes contendo solventes orgânicos tóxicos como o ácido fórmico, NMP e DMF que devem ser tratados antes de serem descartados no meio ambiente. Diante do exposto, os POA's que se baseia principalmente na formação de radicais hidroxilas são capazes de oxidar e mineralizar estes compostos, a partir da combinação de diferentes oxidantes químicos com uma fonte de irradiação, para a geração dos referidos radicais, podendo destruí-los totalmente ou convertê-los em compostos mais simples e inofensivos. De acordo com a literatura estudada ficou constatado que os POA's por meio da fotocatálise $\mathrm{TiO}_{2} / \mathrm{UV}$, do foto-fenton e do $\mathrm{H}_{2} \mathrm{O}_{2} / \mathrm{UV}$, são bastante utilizados no tratamento por não gerar subprodutos e obter eficiências acima de 70\%, podendo chegar em alguns casos próximas a 100\% de 
remoção destes contaminantes. Portanto, esses processos apresentam grande potencial para aplicação no tratamento de efluentes gerados na obtenção de membranas poliméricas.

\section{Agradecimentos}

O presente trabalho foi realizado com apoio da Universidade Estadual da Paraíba, edital PRPGP 001/2021. Além disso, os autores agradecem ao Grupo de Pesquisa em Tratamentos Avançados de Águas - GRUTAA/UEPB, ao Conselho Nacional de Desenvolvimento Científico e Tecnológico - CNPq e à Coordenação de Aperfeiçoamento de Pessoal de Nível Superior - CAPES pelas bolsas concedidas.

\section{Referências}

Afsharnia, M., Kianmehr, M., Biglari, H., Dargahi, A., \& Karimi, A. (2018). Disinfection of dairy wastewater effluent through solar photocatalysis processes. Water Science and Engineering. 11(3), 214-219. https://doi.org/10.1016/j.wse.2018.10.001

Ameta, S. C. Introduction. In. Ameta, S. C., Ameta, R. (Organizadores). (2018). Advanced Oxidation Processes for Waste Water Treatment: Emerging Green Chemical Technology. Academic Press, 1-12.

Anadão, P. (2010). Ciência e Tecnologia de Membranas. Artliber Editora Ltda.

Arcanjo, G. S., Mounteer, A. H., Bellato, C. R., Da Silva, L. M. M., Dias, S. H. B., \& Da Silva, P. R. (2018). Heterogeneous photocatalysis using TiO 2 modified with hydrotalcite and iron oxide under UV-visible irradiation for color and toxicity reduction in secondary textile mill effluent. Journal of Environmental Management. 211, 154-163. https://doi.org/10.1016/j.jenvman.2018.01.033

Arimi, M. M. (2017). Modified natural zeolite as heterogeneous Fenton catalyst in treatment of recalcitrants in industrial effluent. Progress in Natural Science: Materials International, 27 (2), 275-282. https://doi.org/10.1016/j.pnsc.2017.02.001

Athanasekou, C. P., Likodimos, V., \& Falaras, P. (2018). Recent developments of $\mathrm{TiO}_{2}$ photocatalysis involving advanced oxidation and reduction reactions in water. Journal of Environmental Chemical Engineering, 6 (6), 7386-7394. https://doi.org/10.1016/j.jece.2018.07.026

Baker, R. W. (2004). Membrane Technology and Applications, Second Edition, (Eletrônico), John Wiley \& Sons Inc.

Bauer, R., Waldner, G., Fallmann, H., Hagner, M., Krutzler, T., Malato, S., \& Maletzky, P. (1999). The photo-fenton reaction and the TiO $2 /$ UV process for waste water treatment- novel developments. Catalysis Today, 53 (1), 131-144. https://doi.org/10.1016/S0920-5861(99)00108-X

Bila, D. M., Azevedo, E. B., \& Dezotti, M. (2008). Ozonização e Processos Oxidativos Avançados. In. Dezotti, M. Processos e Técnicas para o Controle Ambiental de Efluentes Líquidos. Rio de Janeiro, E-papers, 243-308.

Brasil, Lei. Ministério do Meio Ambiente. Conselho Nacional de Meio Ambiente - Conama. (2005). Resolução nº 430, de 13 de maio de 2011. Dispõe sobre as condições e padrões de lançamento de efluentes e altera a Resolução nº 357. http://www.suape.pe.gov.br/images/publicacoes/CONAMA_n.430.2011.pdf

Brito, N. N., \& Silva, V. B. M. (2012). Processo Oxidativo Avançado e Sua Aplicação Ambiental. Revista eletrônica de engenharia civil, 1 (3), 36-47. https://doi.org/10.5216/reec.v3i1.17000

Chang, C., Chen, J., Lu, M., \& Yang, H. (2005). Photocatalytic oxidation of gaseous DMF using thin film TiO 2 photocatalyst. Chemosphere, 58 (8), 10711078. https://doi.org/10.1016/j.chemosphere.2004.09.072

Chen, Z., Su, H., Hu, D., Jia, F., Li, Z., Cui, Y., Ran, C., Wang, Z., Xu, J., Xiao, T., Li, X., \& Wang, H. Effect of organic loading rate on the removal of DMF, MC and IPA by a pilot-scale AnMBR for treating chemical synthesis-based antibiotic solvent wastewater. Chemosphere, 198, 49-58, 2018. https://doi.org/10.1016/j.chemosphere.2018.01.091

Cheng, X., Zu, L., Jiang, Y., Shi, D., Cai, X., Ni, Y., Lin, S., \& Qin, Y. (2018). A titanium-based photo-fenton bifunctional catalyst of mp-mxene/TiO nanodots for dramatic enhancement of the catalutic efficiency is advanced oxidation processes. Chemical Communications, 54, 11622-11625. http://www.rsc.org/suppdata/c8/cc/c8cc05866k/c8cc05866k1.pdf

Dias, F. F., Silva, P. B. V., Santos, A. F. M. S., Andrade, J. G. P., \& Albuquerque, I. L. T. (2018). Tratamento de efluente têxtil através de processo oxidativo avançado $\left(\mathrm{H}_{2} \mathrm{O}_{2} / \mathrm{TiO}_{2} / \mathrm{UV}\right) . \quad$ Revista Geama - $\quad$ Ciências Ambientais e $\quad$ Biotecnologia, 4 , http://www.ead.codai.ufrpe.br/index.php/geama/article/view/2100

Domènec, X., Jardim, W., \& Litter, M. I. (2001). Processos avanzados de oxidación para la eliminación de contaminantes. In: Eliminación de Contaminantes por Fotocatálisis Heterogénea, 3-26. https://www.researchgate.net/publication/237764122

Dou, P., Song, J., Zhao, S., Xu, S., Li, X., \& He, T. (2019). Novel low cost hybrid extraction-distillation-reverse osmosis process for complete removal of N, N-dimethylformamide from industrial wastewater. Process Safety and Environmental Protection, 130, 317-325. https://doi.org/10.1016/j.psep.2019.08.025

Ebrahimi, I., Gashti, M. P., \& Sarafpour, M. (2018). Photocatalytic discoloration of denim using advanced oxidation process with $\mathrm{H}_{2} \mathrm{O}_{2} / \mathrm{UV}$. Journal of Photochemistry and Photobiology A: Chemistry, 360, 278-288. https://doi.org/10.1016/j.jphotochem.2018.04.053 
El-Alami, W., Sousa, D. G., Rodríguez, C. F., Díaz, O. G., Rodríguez, J. M. D., El Azzouzi, M., \& Araña, J. (2017). Efect of TiF surface interaction on the photocatalytic degradation of phenol, aniline and formic acid. Journal of Photochemistry and Photobiology A: Chemistry, 348, 139-149. https://doi.org/10.1016/j.jphotochem.2017.08.010

Esplugas, S., Yue, P. L., \& Pervez, M. I. (1994). Degradation of 4-chlorophenol by photolytic oxidation. Water Research, 28(6), 1323-1328. https://doi.org/10.1016/0043-1354(94)90297-6

Ferreira, E. S. B., Ferreira, R. S. B., Luna, C. B. B., Araújo, E. M., \& Lira, H. L. (2021). Hollow fiber membranes of several materials and their applications. Research, Society and Development, 10 (1), e55910111206. http://dx.doi.org/10.33448/rsd-v10i1.11206

Figoli, A., Marino, T., Simone. S., Di Nicolo, E., Li, X. M., He, T., Tornaghi, S., \& Drioli, E. (2014). Towards nontoxic solvents for membrane preparation: a review. Green Chemistry, 16, 4034-4059. https://pubs.rsc.org/en/content/articlelanding/2014/gc/c4gc00613e\#!divAbstract

Figoli, A., Simone, S., \& Drioli, E. Polymeric Membranes. In: Hilal, N., Ismail, A. F., Wright, C. J. (Orgs.) (2015). Membrane Fabrication. Boca Raton: CRC Press, 3-44. ISBN: 1482210460

Fioreze, M., Dos Santos, E. P., \& Schmachtenberg, N. (2014). Processos oxidativos avançados: fundamentos e aplicação ambiental. Revista Eletrônica em Gestão, Educação e Tecnologia Ambiental, 18 (1), 79-91. http://dx.doi.org/10.5902/2236117010662

Gohil, J. M., \& Choudhury, R. R. (2019). Introduction to Nanostructured and Nano-enhanced Polymeric Membranes: Preparation, Function, and Application for Water Purification. Nanoscale Materials in Water Purification, 2, 25-57. https://doi.org/10.1016/B978-0-12-813926-4.00038-0

Guerra, M. M. H., Alberola, I. O., Rodriguez, S. M., López, A. A., Merino, A. A., Lopera, A. E., \& Alonso, J. M. Q. (2019). Oxidation mechanisms of amoxicillin and paracetamol in the photo-Fenton solar process. Water Research, 156, 232-240. https://doi.org/10.1016/j.watres.2019.02.055

Habert, A. C., Borges, C. P., \& Nóbrega, R. (2006). Processo de Separação com Membranas. (1ª ed.) E-papers Serviços Editoriais Ltda. ISBN: 857650085X

Hamandi, M., Berhault, G., \& Kochkar, H. (2017). Influence of reduced graphene oxide on the synergism between rutileand anatase $\mathrm{TiO}_{2}$ particles in photocatalytic degradation of formic acid. Molecular Catalysis, 432, 125-130. https://doi.org/10.1016/j.mcat.2017.01.003

Hérissan, A., Meichtry, J. M., Remita, H., Colbeau-Justin, C., \& Litter, M. I. (2017). Reduction of nitrate by heterogeneous photocatalysis over pure and radiolytically modified TiO2 samples in the presence of formic acid. Catalysis Today, 281, 101-108. https://doi.org/10.1016/j.cattod.2016.05.044

Huang, W., Bianco, A., Brigante, M., \& Mailhot, G. (2018). UVA-UVB activation of hydrogen peroxide and persulfate for advanced oxidation processes: Efficiency, mechanism and effect of various water constituents. Journal of Hazardous Materials, 347, 279-287. https://doi.org/10.1016/j.jhazmat.2018.01.006

Kwon, S., Lin, T. C., \& Iglesia, E. (2020). Elementary steps and site requirements in formic acid dehydration reactions on anatase and rutile $\mathrm{TiO}_{2}$ surfaces. Journal of Catalysis, 383, 60-76. https://doi.org/10.1016/j.jcat.2019.12.043

Lima, C. A. P., Araujo, B. A., Silva, K. S., Silva, C. B., Lima, G. G. C., Vieira, F. F., \& Medeiros, K. M. (2020). Advanced oxidative process by heterogeneous photocatalysis for chemical laboratories effluents treatment. Desalination and Water Treatment, 174, $248-257$. https://doi:10.5004/dwt.2020.24894

Loh, C. H., Wu, B., Ge, L., Pan, C., \& Wang, R. (2018). High-strength N-methyl-2-pyrrolidone-containing process wastewater treatment using sequencing batch reactor and membrane bioreactor: A feasibility study. Chemosphere, 194, 534-542. https://doi.org/10.1016/j.chemosphere.2017.12.013

M’bra, I. C., García-Muños, P., Drogui, P., Keller, N. Trokourey, A. \& Robert, D. (2019). Heterogeneous photodegradation of Pyrimethanil and its commercial formulation with $\mathrm{TiO}_{2}$ immobilized on $\mathrm{SiC}$ foams. Journal of Photochemistry and Photobiology A: Chemistry, 368, 1-6. https://doi.org/10.1016/j.jphotochem.2018.09.007

Ma, T., Garg, S., Miller, C. J., \& Waite, T. D. (2015). Contaminant degradation by irradiated semiconducting silver chloride particles: Kinetics and modelling. Journal of Colloid and Interface Science, 446, 366-372. https://doi.org/10.1016/j.jcis.2014.11.069

Mariani, M. L., Brandi, R. J., Cassano, A. E., \& Zalazar, C. S. (2013). A kinetic model for the degradation of dichloroacetic acid and formic acid in water employing the $\mathrm{H}_{2} \mathrm{O}_{2} / \mathrm{UV}$ process. Chemical Engineering Journal, 225, 423-432. https://doi.org/10.1016/j.cej.2013.03.098

Mena, E., Rey, A., \& Beltrán, F. J. (2018). $\mathrm{TiO}_{2}$ photocatalytic oxidation of a mixture of emerging contaminants: A kinetic study independent of radiation absorption based on the direct-indirect model. Chemical Engineering Journal, 339, 369-380. https://doi.org/10.1016/j.cej.2018.01.122

Miller, K. L., Lee, C. W., Falconer, J. L., \& Medlin, J. W. (2010). Effect of water on formic acid photocatalytic decomposition on $\mathrm{TiO}_{2}$ and Pt/TiO 2 . Journal of Catalysis, 275 294-299. https://doi.org/10.1016/j.jcat.2010.08.011

Mrowetz, M., \& Selli, E. (2006). Photocatalytic degradation of formic and benzoic acids and hydrogen peroxide evolution in $\mathrm{TiO}_{2}$ and $\mathrm{ZnO}_{\text {water suspension. }}$ Journal of Photochemistry and Photobiology A: Chemistry, 180, 15-22. https://doi.org/10.1016/j.jphotochem.2005.09.009

Negishi, N., Sugasawa, M., Miyazaki, Y., Hirami, Y., \& Koura, S. (2019). Effect of dissolved silica on photocatalytic water purification with a TiO ${ }_{2}$ ceramic catalyst. Water Research, 150, 40-46. https://doi.org/10.1016/j.watres.2018.11.047

Pan, Z., Song, C., Li, L., Wang, H., Pan, Y., Wang, Y., \& Feng, X. (2019). Membrane technology coupled with electrochemical oxidation processes for organic wastewater treatment: recente advances and future prospects. Chemical Engineering Journal, 1-19. https://doi.org/10.1016/j.cej.2019.01.188

Parrino, F., Camera-Roda, G., Loddo, V., Palmisano, G., \& Augugliaro, V. (2014). Combination of ozonation and photocatalysis for purification of aqueous effluents containing formic acid as probe pollutant and bromide ion. Water Research, 50, 189-199. https://doi.org/10.1016/j.watres.2013.12.001

Pascoal, S. A., Silva, C. B., Da Silva, K. S., De Lima, G. G. C., De Medeiros, K. M., \& De Lima, C. A. P. (2020). Treatment by TiO $2 / \mathrm{UV}$ of wastewater generated in polymeric membranes production. Desalination and Water Treatment, 207, 30-32. https://doi.org/10.5004/dwt.2020.26390 
Rauf, M. A., Meetani, M., Khaleel, A., \& Ahmed, A. (2015). Photocatalytic degradation of methylene blue using a mixed catalyst and product analysis by LC/MS. Chemical Engineering Journal, 157 (2-3), 373-378. https://doi.org/10.1016/j.cej.2009.11.017

Razali, M., Kim, J. F., Attfield, M., Budd, P. M., Drioli, E., Lee, Y. M., \& Szekely, G. (2015). Sustainable wastewater treatment and recycling in membrane manufacturing. Green Chemistry, 17, 5196-5205. http://www.rsc.org/suppdata/c5/gc/c5gc01937k/c5gc01937k1.pdf

Ribeiro, J. P., Abdala Neto, E. F., Parente, T. C., Nascimento, R. F., Barros, A. L., Oliveira, A. G., \& Barros, F. C. F. Princípios Básicos. (2017). Processos Oxidativos Avançados: Fundamentos e Aplicações em Matrizes Ambientais. Imprensa Universitária, 11-40. http://www.repositorio.ufc.br/handle/riufc/32127

Riboni, F., Dozzi, M. V., Paganini, M. C., Giamello, E., \& Selli, E. (2017). Photocatalytic activity of $\mathrm{TiO}_{2}-\mathrm{WO}_{3}$ mixed oxides in formic acid oxidation. Catalysis Today, 287, 176-181. https://doi.org/10.1016/j.cattod.2016.12.031

Sadi, A. B., Bilali, R. K. A., Abubshait, S. A., \& Kochkar, H. (2020). Low temperature design of titanium dioxide anatase materials decorated with cyanuric acid for formic acid photodegradation. Journal of Saudi Chemical Society, 24, 351-363. https://doi.org/10.1016/j.jscs.2020.01.009

Sang, W., Cui, J., Mei, L., Zhang, Q., Li, Y., Li, D., Zhang, W., \& Li, Z. (2019). Degradation of liquid phase N, N-dimethylformamide by dielectric barrier discharge plasma: Mechanism and degradation pathways. Chemosphere, 236, 124401. https://doi.org/10.1016/j.chemosphere.2019.124401

Silva, A. F. P. S., Araújo, E. M., Lira, H. L., Ferreira, R. S. B., Medeiros, V. N., \& Oliveira, S. S. L. (2021). Synthesis of polysulfone/alumina hollow fiber membranes for water treatment in the presence of indigo blue dye. Research, Society and Development, 10(1), e18610110863. http://dx.doi.org/10.33448/rsdv10i1.10863

Silva, M. B. R., Azevedo, P. V., \& Alves, T. L. B. (2014). Análise da degradação ambiental do alto curso da bacia hidrográfica do rio Paraíba. Boletim Goiano de Geografia (Online), 34 (1), 35-53. https://doi.org/10.5216/bgg.v34i1.29314

Turki, A., Guillard, C., Dappozze, F., Berhault, G., Ksibi, Z., \& Kochkar, H. (2014). Design of $\mathrm{TiO}_{2}$ nanomaterials for the photodegradation of formic acid Adsorption isotherms and kinetics study. Journal of Photochemistry and Photobiology A: Chemistry, 279, 8-16. https://doi.org/10.1016/j.jphotochem.2014.01.008

Ulliman, S. L., Mckay, G., Rosario-Ortiz, F. L., \& Linden, K. G. (2018). Low levels of iron enhance UV/ $\mathrm{H}_{2} \mathrm{O}_{2}$ efficiency at neutral pH. Water Research, 130, 234-242. https://doi.org/10.1016/j.watres.2017.11.041

Vieira, S. M. M., Costa, T. B., \& Naves, F. L. (2018). Utilização de processo oxidativo avançado (fotofenton) no tratamento de efluente à base de gasolina comercial. The Journal of Engineering and Exact Sciences - JCEC, 4 (1). https://doi.org/10.18540/jcecvl4iss1pp0014-0018

Wan, L., Sheng, J., Chen, H., \& Xu, Y. (2013). Different recycle behavior of $\mathrm{Cu}^{2+}$ and $\mathrm{Fe}^{3+}$ ions for phenol photodegradation over $\mathrm{TiO}_{2}$ and $\mathrm{WO}_{3}$. Journal of Hazardous Materials, 262, 114-120. https://doi.org/10.1016/j.jhazmat.2013.08.002

Wang, H. H., Jung, J. T., Kim, J. F., Kim, S., Drioli, E., \& Lee, Y. M. (2019). A novel green solvent alternative for polymeric membrane preparation via nonsolvent-induced phase separation. Journal of Membrane Science, 574, 44-54. https://doi.org/10.1016/j.memsci.2018.12.051

Wang, S., Shiraishi, F., \& Nakano, K. (2002). A synergistic effect of photocatalysis and ozonation on decomposition of formic acid in an aqueous solution. Chemical Engineering Journal, 87 (2), 261-271. https://doi.org/10.1016/S1385-8947(02)00016-5

Zolfaghari, A., Mortaheb, H. R., \& Meshkini, F. (2011). Removal of N-methyl-2-pyrrolidone by photocatalytic degradation in a batch reactor. Industrial \& Engineering Chemistry Research, 50 (16), 9569-9576. https://doi.org/10.1021/ie200702b 